\title{
Frontline Frustration: The Experience of Point-of-Sale Cause Marketing from the Cashier and Customer Perspectives: An Abstract
}

\author{
Debra Z. Basil, Mary S. Runte, Bola Fowosere, and Alexa Villanueva
}

\begin{abstract}
Cause-related marketing (CRM) is a popular business strategy to improve brand image and increase profitability while raising funds and awareness for charitable causes. This practice involves a company and charity partnering on a marketoriented endeavor to benefit both parties. Increasingly, businesses are conducting a form of CRM at the cash register by requesting point-of-sale donations (POSD) for a cause or nonprofit, as customers pay for their purchases. This research examines frontline perception of this practice. Specifically, we examine how both customers and cashiers view POSD requests. Very little academic research to date has examined this topic. Extant POSD research primarily involves surveys from the practitioner realm. These offer valuable insights but remain at a somewhat general level. To gain a deeper understanding of how those most intimately impacted by the solicitation process view it, we adopt a qualitative research approach. Two customer focus groups and three cashier focus groups were conducted to explore this issue. Results suggest that both customers and cashiers find the practice to be somewhat uncomfortable. Participants on both sides of the cash register want more information on how the money is used and if the efforts genuinely benefit the targeted cause. Additionally, to some extent both customers and cashiers feel that the cashiers do not have sufficient information about these efforts to share with customers. Finally, both customers and cashiers are generally supportive of POSD efforts, despite their apprehensions. Thus, the ends (helping a worthy cause) appear to justify the means (POSD). This may explain the apparent discrepancy between our somewhat negative findings and the relatively positive findings of extant surveys. By adopting a qualitative approach, we have exposed certain negative process components that rarely surface through other means.
\end{abstract}

Project funded in part by the Chinook Summer Research Awards, University of Lethbridge.

D. Z. Basil $(\bowtie) \cdot$ M. S. Runte $\cdot$ B. Fowosere · A. Villanueva

University of Lethbridge, Lethbridge, Canada

e-mail: debra.basil@uleth.ca; mary.runte@uleth.ca; bola.fowosere@uleth.ca;

alexa.villanueva@uleth.ca 